\title{
Extraction and characterization of yeast extract bioethanol byproduct from empty palm oil bunch for raw material of cosmetic products
}

\author{
Muhamad Sahlan ${ }^{1,2^{*}}$, Muhammad Saefuddin ${ }^{1}$, Muryanto $^{3}$, Heri Hermansyah ${ }^{1}$ and Anondho Wijanarko ${ }^{1}$ \\ ${ }^{1}$ Department of Chemical Engineering, Faculty of Engineering, Universitas Indonesia, Depok, 16425, Depok, Indonesia \\ ${ }^{2}$ Research Center of Biomedical Engineering, Faculty of Engineering, Universitas Indonesia, Depok, 16425, Indonesia \\ ${ }^{3}$ Chemical Research Centre, Indonesian Institute of Science, Puspiptek area, Serpong, Tangerang Selatan 15314, Indonesia.
}

\begin{abstract}
Ethanolic fermentation can produce byproducts such as yeast containing intracellular amino acid that is used as a raw material of cosmetics. Residual yeast fermentation as sludge was dissolved and extracted by autolysis at $50^{\circ} \mathrm{C}$ for 24 hours, so we get the product in the form of intracellular content of the yeast Saccharomyces cerevisiae. Purification of dye and odor yeast extract was conducted by using an activated carbon column adsorption with ratio 1.5:10 yeast extract solution $(\mathrm{g} / \mathrm{mL})$ for six times recycle or until it reaches the absorbance value of 0.020 . The content of yeast extract in the form of amino acids was analyzed by High-Pressure Liquid Chromatography method. Analysis of the feasibility test yeast extract as cosmetic raw materials made through the pigment deposition method by inhibit tyrosinase activity. $0.05 \mathrm{~g}$ yeast extract before adsorption (pale yellow) produce $62 \%$ inhibition of tyrosinase $3130 \mathrm{U} / \mathrm{mL}$. Dry yeast extract after adsorption (odorless) had $96 \%$ inhibition of tyrosinase $313 \mathrm{U} / \mathrm{mL}$, whereas placental extract by $89 \%$ inhibition of tyrosinase $313 \mathrm{U} / \mathrm{mL}$. These results indicate odorless yeast extract can replace placental extract as an alternative to cosmetic raw materials.
\end{abstract}

\section{Introduction}

Presidential Regulation No.5 of 2006 on National Energy Policy in 2005 to target the use of alternative fuels such as biofuels reached $5 \%$ in 2025. Development of alternative energy sources is carried out based on the existence of the number of available sources of raw materials and microorganisms which can be used in each region of the state. Alternative energy sources continue to grow until the second generation. Bioethanol made from oil palm empty fruit bunches (EFB) is one example of the second generation of alternative energy are preferred in Indonesia because of the content of lignocellulose as a raw material for the production of bioethanol EFB approximately $41-47 \%$. The government of Indonesia support alternative energy with trying to encourage the sustainable use of natural resources through the development of sectoral policies, with the mandatory certification scheme established by the government through the Indonesian Sustainable Palm Oil (ISPO) in the palm oil sector [1].

Utilization of processed palm oil is not limited to the main product but has achieved scope byproduct production. Fermentation has important role in bioethanol production because this process will convert glucose into ethanol. The most common microorganism used in fermentation process is Saccharomyces cerevisiae [2]. $S$. cerevisiae as a byproduct of the production of bioethanol made from raw EFB contains an intracellular form of amino acids, and nucleic acids can be used as cell regeneration or repair of damaged skin cells. Some of the problems encountered in generating yeast extract are when the extraction process with high temperature can change the color becomes pale due to yeast extract aminocarbonyl reaction that creates the color brown [3]. One solution is to separate the yeast extraction from substances with color and special treatment methods that can be utilized with both high values and as an alternative raw material of cosmetic products.

\section{Material and Methods}

\subsection{Materials}

Raw materials in the form of bioethanol fermentation result from Indonesian Research Center of Chemistry (LIPI) in Serpong, Indonesia. The enzyme tyrosinase from Sigma Aldrich. L-tyrosine from HIMEDIA. Technical activated carbon from Basic Chemistry Laboratory Departement of Chemical Engineering, Faculty of Engineering, Universitas Indonesia.

\footnotetext{
* Corresponding author: sahlan@che.ui.ac.id
} 


\subsection{Extraction}

The solution was centrifuged at $5000 \mathrm{rpm}$ fermented for 30 minutes. Every 1.5 grams of precipitate redissolved with ten $\mathrm{mL}$ of distilled water. Then Autolysed at a temperature of $50^{\circ} \mathrm{C}$ for 24 hours. Centrifugation was repeated to obtain a supernatant solution of yeast extract pale yellow. The intensity of the color of the pale yellow solution of yeast extract was measured using a UV-vis spectrophotometer Spectrocuant in Laboratory of Bioprocess Engineering, of Chemical Engineering, Faculty of Engineering, Universitas Indonesia at a wavelength of $420 \mathrm{~nm}$.

Dried yeast extract was using the freeze-drying method in LIPI Cibinong, Indonesia. Freeze drying is a drying method on the triple temperature water to prevent the breakdown of amino acids in yeast extract solution.

\subsection{Adsorption of Yeast Extract}

Each $30 \mathrm{~mL}$ of yeast extract pale yellow mass adsorbed by technical activated carbon variations as much as $10 \mathrm{~g}$, $15 \mathrm{~g}, 20 \mathrm{~g}, 25 \mathrm{~g}$, and $30 \mathrm{~g}$. Color absorbance values extract solution after adsorption (odorless) measured at each variation to determine the effect of the amount of adsorbent on the adsorbate amount that can be absorbed. Also, variations in the use made of the repetition of the adsorbent (activated carbon technical) to absorb the same re-extract solution to generate the absorbance value of 0.020 .

\subsection{Amino Acid Analysis}

Analysis performed on the amino acid content of yeast extract solution before adsorption (pale yellow) and after adsorption (odorless) using HPLC in Saraswanti Indo Gentech Bogor Laboratory, Indonesia.

\subsection{Inhibition of Tyrosinase Activity Test}

Tyrosinase activity inhibition assay consisted of control (no inhibitor) and two inhibitors such as placenta extract, and yeast extract. Each sample solution consisted of $3 \mathrm{~mL}$ of phosphate buffer (pH 6.8) $2.5 \mathrm{~mL}$, L-tyrosine (1.5 mM) $0.4 \mathrm{~mL}$, the enzyme tyrosinase $(3130 \mathrm{U} / \mathrm{mL}) 0.1 \mathrm{~mL}$, and extracts yeast $50 \mathrm{mg}$. The sample solution is tested every minute using Spectroquant with a wavelength of $475 \mathrm{~nm}$ for 10 minutes. Calculation of $\%$ adsorption and \% inhibition can use the Equation 1 below,

$\%$ adsorption or $\%$ inhibition $=\left[\frac{(A-B)}{A}\right] \times 100 \%$ (1) (1)

where $\mathrm{A}$ is the absorbance value of the control variable, and $B$ is the absorbance value of the sample.

\section{Results and Discussion}

\subsection{Adsorption of Yeast Extract}

Adsorption of yeast extract shown in Figure 1. It illustrates that more recycling is done, then the change in $\%$ adsorption between the smaller recycle. At first, the surface of activated carbon has not coated by adsorbate. The longer the dye will cover the activated carbon surface so the quality of continuous activated carbon that was used will decrease [4].

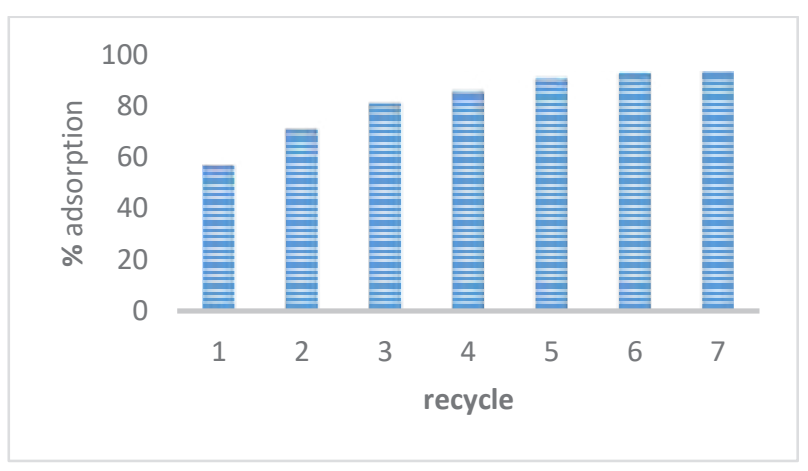

Fig. 1. Effect of recycling on $\%$ adsorption

Effect of the adsorbent ratio of \% adsorption shown in Figure 2. It shows that the higher the ratio adsorbent (01 ), the greater the $\%$ adsorption to be obtained. The more surface area of activated carbon, the more adsorbate that can be absorbed [5]. \% Adsorption experiments obtained from the ratio adsorbent are respectively $57 \%, 74 \%, 82 \%$, $91 \%$, and $94 \%$.

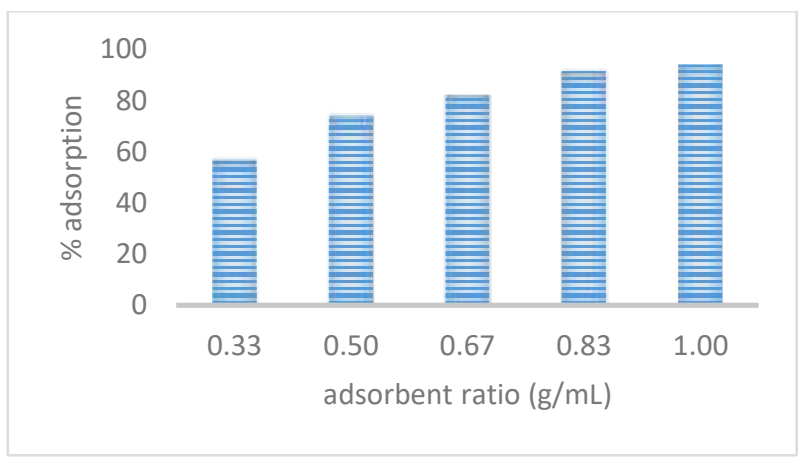

Fig. 2. Effect of adsorbent ratio of $\%$ adsorption

\subsection{Amino Acid Analysis}

Amino acids analysis presented in Figure 3. It describes the effect of amino acids on yeast extract before and after adsorption. The situation occurs because activated carbon can adsorb several types of amino acids [6]. All types of amino acids can be adsorbed due to amino acids adsorbed not only on the conditions of free amino acids in the form of protein but consist of various amino acids. 


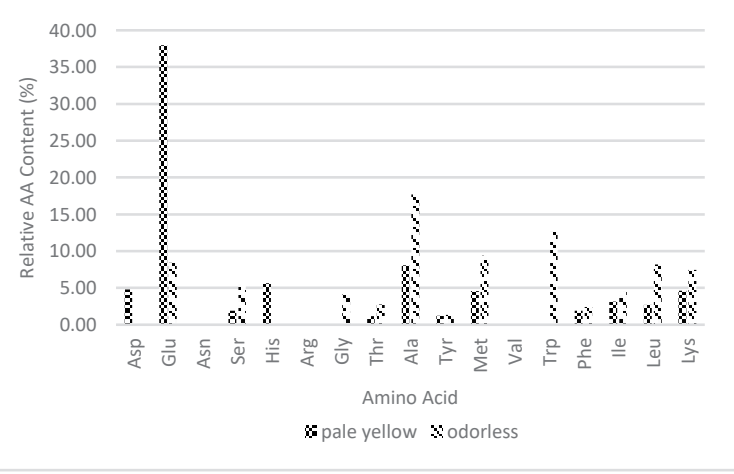

Fig. 3. Amino Acid Characteristic

\subsection{Inhibition of Tyrosinase Activity}

In this experiment used for comparison between placenta and yeast extract on tyrosinase activity inhibition assay [7]. Placenta extract is a cosmetic raw material that is debatable legality regarding the religion of Islam [8]. Therefore, it is expected to replace the yeast extract as an ingredient placenta extract cosmetic raw.

Based on the trial results, the characteristics of inhibition of tyrosinase activity in the control and yeast extract pale yellow \% inhibition produces very small. It shows that the concentration of yeast extract pale yellow solution still can not inhibit tyrosinase activity. Therefore, to improve the concentration of the extract by drying the extract solution into a solid by the freeze-drying method [9].

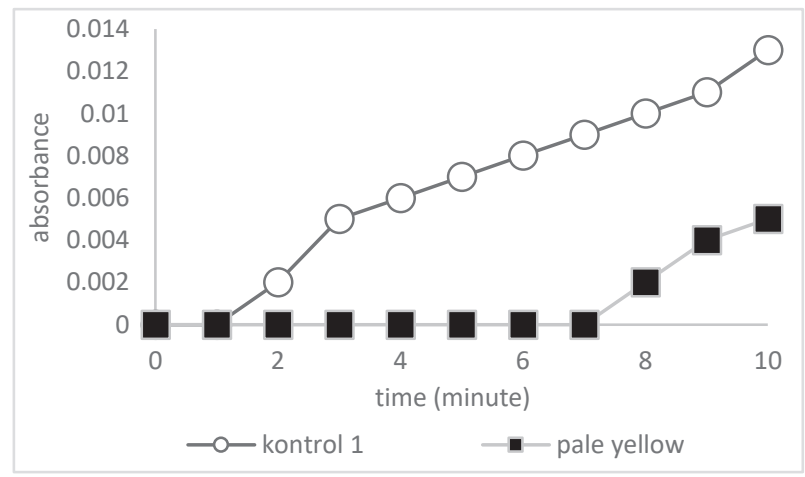

Fig. 4a. Absorbance of tyrosinase enzyme activity (pale yellow)

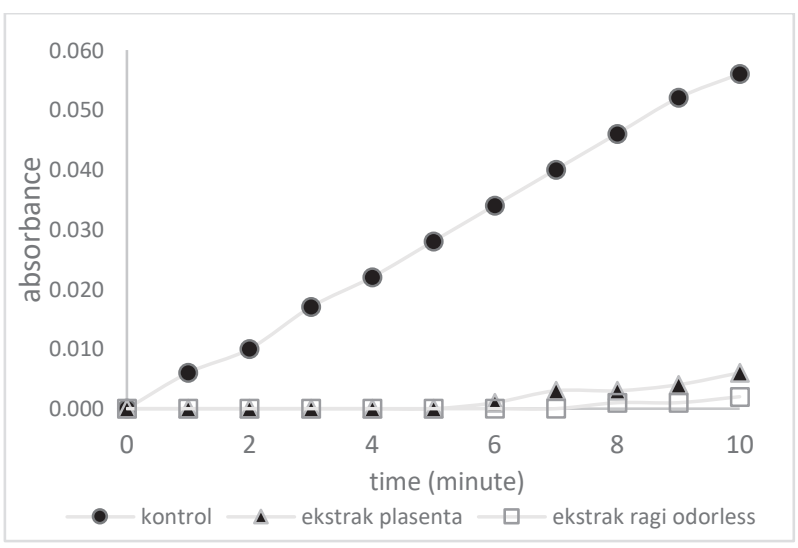

Fig. 4b. Absorbance of tyrosinase enzyme activity (odorless)
Characteristic absorbance values due to the activity of the tyrosinase enzyme that converts tyrosine into melanin (brown pigment) presented in Figure 4. From the graph looks the same minute produces absorbance difference that proves tyrosinase activity can be inhibited by inhibitors such as placenta extract, yeast extract yeast extract pale yellow and odorless. Next will be analyzed on the $\%$ inhibition of both inhibitors on the activity of the enzyme tyrosinase.

The results of the calculation of $\%$ inhibition of tyrosinase activity presented in Figure 5 , in minute 10 with the tyrosinase enzyme concentration $313 \mathrm{U} / \mathrm{mL}$. Through experiments that have been conducted, placenta extract resulted in $89 \%$ inhibition of tyrosinase activity, while yeast extract dry odorless can produce $96 \%$ inhibition of tyrosinase activity. At different enzyme concentrations $3130 \mathrm{U} / \mathrm{mL}$, yeast extracts can produce a pale yellow. It show that dryied yeast extract contain higher yeast extract concentration than liquid / solution.

Odorless dry yeast extracts can replace placental extract as a cosmetic raw material because it has a \% inhibition of tyrosinase enzyme activity is higher.

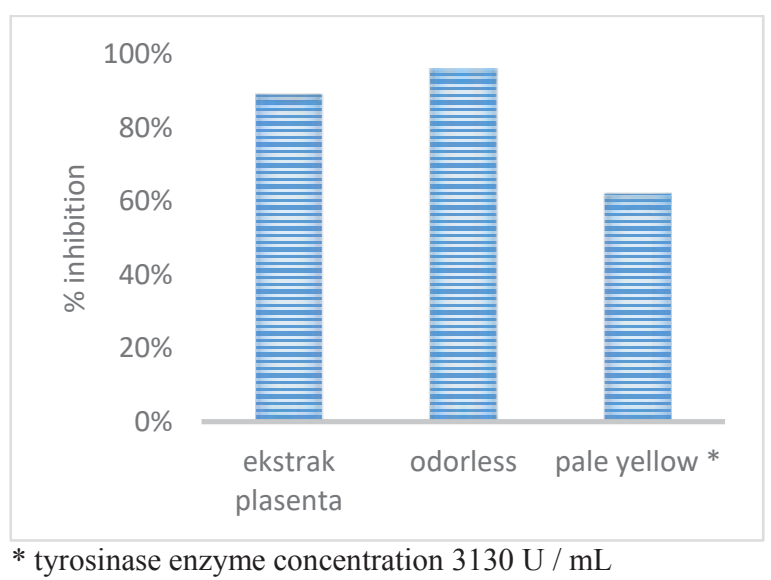

Fig. 5. \% Inhibition of tyrosinase activity

\section{Conclusion}

Purification of yeast extract color and flavor can be done using a column of activated carbon adsorbent with the best ratio of $1: 1(\mathrm{~g} / \mathrm{mL})$ and through $6 \mathrm{x}$ recycle so that the absorbance values obtained yeast extract solution after adsorption (odorless) to 0.020 at a wavelength of $420 \mathrm{~nm}$.

Drying yeast extract needs to be done to get the yeast extract concentration higher than it would be liquid / solution. Odorless dry yeast extracts can replace placental extract as a cosmetic raw material because it has $a \%$ inhibition of tyrosinase enzyme activity is higher.

This research/article's publication is fully supported by the United States Agency for International Development (USAID) through the Sustainable Higher Education Research Alliance (SHERA) Program for Universitas Indonesia's Scientific Modeling, Application, Research and Training for City-centered Innovation and Technology (SMART CITY) Project, Grant \#AID-497-A-1600004, Sub Grant \#IIE-00000078-UI-1 (No.0139/UN2.R3.SC/HKP.05.01/2018) 


\section{Conflict of Interest}

We have no conflicts of interest to disclose.

\section{References}

1. Brandi, C. et al. Sustainability Certification in the Indonesian Palm Oil Sector. (The German Development Institute, Bonn, 2013).

2. Hermansyah, H. et al. Effect of aeration and nutrients on Saccharomyces cerevisae cultivation using lignocellulosic hydrolisate from empty fruit bunch. Int. J. Technol. 7, 1110-1118 (2015).

3. Kado, H., Shibata, T., Kobayashi, F., Kubota, M. \& Machi, N. Process for Producing Yeast Extract. (2000).

4. Gupta, V. K. \& Suhas. Application of low-cost adsorbents for dye removal - A review. J. Environ. Manage. 90, 2313-2342 (2009).

5. Mistar, E., Ahmad, S., Muslim, A., Alfatah, T. \& Supardan, M. Preparation and characterization of a high surface area of activated carbon from Bambusa vulgaris - Effect of $\mathrm{NaOH}$ activation and pyrolysis temperature. in IOP Conf. Series: Materials Science and Engineering 334 (3rd IOP Publishing, 2018). doi:10.1088/1757-899X/334/1/012051

6. Silva, K. C. G., Amaral, T. N., Junqueira, L. A., de Oliveira Leite, N. \& de Resende, J. V. Adsorption of protein on activated carbon used in the filtration of mucilage derived from Pereskia aculeata Miller. South African J. Chem. Eng. 23, 42-49 (2017).

7. Yamasaki, M. et al. Placental extracts induce the expression of antioxidant enzyme genes and suppress melanogenesis in B16 melanoma cells. Nat. Prod. Res. 29, 2103-2106 (2015).

8. Peng, K. \& Karim, R. H. A. Good Manufacturing Practices for Halal Pharmaceuticals. Pharm. Eng. 33, 4-7 (2013).

9. Juliflora, P. Lyophilization / Freeze Drying - A Review. World J. Pharm. Res. 4, 1168-1177 (2015). 